\title{
Penerapan Model Pembelajaran Kooperatif Tipe TAI (Team Assisted Individualization) Untuk Meningkatkan Pemahaman Siswa Dalam Materi Macam-Macam Sujud Pada Kelas VIII SMP Negri 2 Sampoiniet
}

\author{
Malum Manik, S.Pd.I \\ SMP Negri 2 Sampoiniet
}

\begin{abstract}
Abstrak
Penelitian ini berjudul Penerapan Model Pembelajaran Kooperatif Tipe TAI sebagai upaya peningkatan prestasi belajar Pendidikan Agama Islam (PAI) siswa kelas VIII SMP Negeri 2 Sampoiniet pada materi Belajar Macam-macam Sujud. Penelitian ini bertujuan untuk meningkatkan pemahaman siswa dan mengetahui aktifitas belajar siswa kelas VIII SMP Negeri 2 Sampoiniet dalam pembelajaran PAI pada materi Macam-macam Sujud dengan penerapan model pembelajaran kooperatif Tipe TAI. Penelitian ini merupakan peneliian tindakan kelas dengan dua siklus. Jenis penelitian ini merupakan deskriptif. Data dikumpulkan melalui kuisioner observasi aktifitas guru dan aktifitas siswa selama proses pembelajaran serta lembar evaluasi untuk tes. Data kemudian diolah dengan tekhnik persentase. Berdasarkan hasil penelitian menunjukkan pada siklus I secara rata-rata prestasi siswa mencapai 69\% termasuk kategori "baik", , dan pada siklus II sudah menjadi 82, ini masuk kategori "Amat Baik". Hasil tes menunjukkan dari siklus I dinyatakan tuntas peningkatan sebanyak 25 siswa pada siklus II. Berdasarkan hasil penelitian dapat disimpulkan bahwa penerapan model pembelajaran kooperatif Tipe TAI dapat meningkatkan prestasi belajar siswa kelas VIII SMP Negeri 2 Sampoiniet Kecamatan Sampoiniet Kabupaten Aceh Jaya.

Kata Kunci : Pembelajaran PAI, Model Pembelajaran, Kooperatif Tipe TAI, pemahaman siswa.
\end{abstract}

\section{PENDAHULUAN}

Kualitas pendidikan meliputi diberbagai sektor dan jenjang pendidikan, termasuk jenjang pendidikan dasar. Keberhasilan pendidikan banyak dipengaruhi oleh berbagai faktor termasuk guru. Guru yang profesional akan selalu berupaya untuk meningkatkan pemahaman siswa terhadap materi yang diajarkan. Hal ini sejalan dengan tujuan pendidikan nasional yang dirinci sebagai berikut :

1. Mendidik adalah usaha sadar untuk meningkatkan dan menyiapkan peserta didik melalui kegiatan bimbingan, pengajaran dan atau latihan bagi perannya dimasa yang akan datang.

2. Peserta didik adalah anggota masyarakat yang berusaha mengembangkan dirimelalui proses pendidikan pada jalur dan jenjang pendidikan tertentu. Peserta didik adalah anggota masyarakat yang berusaha mengembangkan diri melalui proses pendidikan pada jalur dan jenjang pendidikan tertentu. (Ngalim Purwanto, 1997: 42)

Dalam upaya meningkatkan proses belajar, guru harus berupaya menciptakan strategi yang cocok, sebab dalam proses belajar mengajar yang bermakna, keterlibatan 
siswa sangatlah penting, hal ini sesuai dengan pendapat Muhamad Ali, (1983 : 12) yang menyebutkan bahwa kadar pembelajaran akan bermakna apabila :

1. Adanya keterlibatan siswa dalam proses belajar mengajar.

2. Adanya keterlibatan intelektual-emosional siswa baik melalui kegiatan menganalisa, berbuat dan pembentukan sikap.

3. Adanya keikutsertaan siswa secara kreatif dalam menciptakan situasi yang cocok untuk berlangsungnya proses belajar mengajar.

Dari 25 siswa Kelas VIII SMP Negeri 2 Sampoiniet Kecamatan Sampoiniet Kabupaten Aceh Jaya Tahun Ajaran 2019/2020 yaitu 17 laki-laki dan 8 parempuan . Hanya 13 orang yang tuntas belajar sedangkan 12 orang siswa lainnya belum tuntas, hal ini mendorong kami untuk melakukan Penelitian Tindakan Kelas ini. Berkenaan dengan hal tersebut di atas, model Pembelajaran Kooperatif Tipe TAI dalam pembelajaran akan lebih bermakna, sebab dengan menggunakan model Pembelajaran kooperatif Tipe TAI siswa akan terlibat secara langsung dalam proses pembelajaran.

Mata pelajaran PAI merupakan salah satu mata pelajaran yang diajarkan di sekolah tingkat pertama, dan merupakan hasil kegiatan manusia berupa pengetahuan, gagasan dan konsep yang terorganisasi tentang alam sekitar, yang diperoleh dari pengalaman melalui serangkaian proses ilmiah antara lain penyelidikan, penyusunan dan pengujian gagasan-gagasan. Kehadiran model Pembelajaran Kooperatif Tipe TAI dalam pembelajaran PAI akan lebih mempermudah bagi guru dalam menyampaikan materi yang akan diajarkan kepada siswa.

Berdasarkan hasil renungan yang penulis lakukan setelah melaksanakan pembelajaran PAI tentang materi belajar Macam-macam sujud, yang dilanjutkan dengan evaluasi, tetapi hasilnya tidak memuaskan, maka penulis sebagai guru kelas menyadari bahwa kesalahan berada pada guru bukan pada siswa, antara lain pembelajaran berpusat pada guru, keterlibatan siswa dalam pembelajaran kurang ada kesempatan untuk terlibat langsung dalam proses pembelajaran yang mengakibatkan siswa pasif dan hasil evaluasi. Dari 25 siswa hanya 13 orang yang tuntas belajar atau setara dengan 52\%. Dengan KKM Mata pelajaran PAI adalah 72, berlatar belakang dari permasalahan tersebut, dipandang perlu melaksanakan Penelitian Tindakan Kelas, sebab Penelitian Tindakan Kelas merupakan suatu penelitian yang bertujuan untuk memperbaiki dan meningkatkan mutu pembelajaran yang bersifat individual dan luwes. (Kasihani Kasbolah, 1998:22).

\section{Tujuan Penelitian}

a Ingin mengetahui dan memahami rencana pembelajaran IPA tentang belajar Macammacam sujud, dengan menggunakan Model Pembelajaran Kooperatif Tipe TAI di Kelas VIII SMP Negeri 2 Sampoiniet Kecamatan Sampoiniet Kabupaten Aceh Jaya Ingin mengetahui dan memahami proses berlangsungnya pembelajaran IPA dalam belajar Macam-macam sujud di Kelas VIII SMP Negeri 2 Sampoiniet dengan menggunakan Model Pembelajaran Kooperatif Tipe TAI.

c Ingin mengetahui kemampuan dan kelemahan siswa di Kelas VIII SMP Negeri 2 Sampoiniet Kecamatan Sampoiniet Kabupaten Aceh Jaya dalam materi belajar Macam- 
macam sujud setelah pembelajaran menggunakan Model Pembelajaran Kooperatif Tipe TAI.

\section{KAJIAN PUSTAKA \\ Pengertian Belajar}

Untuk mencapai tujuan agar siswa dapat meningkatkan hasil belajar yang baik, terlebih dahulu siswa memahami pengertian dari belajar. Belajar adalah suatu kegiatan yang membawa perubahan pada individu yang belajar. Perubahan itu tidak hanya mengenai jumlah pengetahuan melainkan juga dalam bentuk kecakapan, kebiasaan, sikap, pengertian, dan pengahargaan, minat, pendeknya mengenai segala aspek atau pribadi seseorang. (Nasution, $1995: 35$ ).

Menurut pengertian secara psikologis belajar merupakan suatu proses perubahan tingkah laku sebagai hasil dari interaksi dengan lingkungannya (Slamito, 2002 : 2). Winkel (1989 : 15) "mengemukakan bahwa proes belajar pada manusia merupakan proses siklus yang berlangsung dalam mengaktifkan subjek dengan lingkungan yang menghasilkan perubahan".

\section{Pengertian Mengajar}

Selain siswa harus tahu pengertian belajar, gurupun harus tahu pengertian mengajar. Menurut Slameto (1995:29) "mengajarkan adalah penyerahan kebudayaan berupa pengalaman dan kecakapan kepada anak didik". Sudjono (2000 : 37) "mengatakan bahwa mengajar adalah sebagai alat yang direncanakan melalui berbagai kegiatan seoptimal mungkin".

Dari uraian di atas dirumuskan definisi bahwa mengajar adalah suatu kegiatan membimbing dan mengorganisasikan lingkungan sekitar anak didik agar tercipta lingkungan belajar yang konduktif. Guru didalam menyampaikan proses pembelajaran harus dapat menemukan dan menggunakan metode yang cepat dan aktif.

\section{Pembelajaran Kooperatif}

Model pembelajaran kooperatif adalah rangkaian kegiatan belajar yang dilakukan oleh siswa dalam kelompok-kelompok tertentu untuk mencapai tujuan pembelajaran yang telah dirumuskan.

Slavin dalam Isjoni (2009: 15) pembelajaran kooperatif adalah suatu model pembelajaran dimana siswa belajar dan bekerja dalam kelompok-kelompok kecil secara kolaboratif yang anggotanya 5 orang dengan struktur kelompok heterogen. Sedangkan menurut Sunal dan Hans dalam Isjoni (2009: 15) mengemukakan bahwa pembelajaran kooperatif merupakan suatu cara pendekatan atau serangkaian strategi yang khusus dirancang untuk memberi dorongan kepada siswa agar bekerja sama selama proses pembelajaran. Selanjutnya Stahl dalam Isjoni (2009: 15) menyatakan pembelajaran kooperatif dapat meningkatkan belajar siswa lebih baik dan meningkatkan sikap saling tolong-menolong dalam perilaku sosial.

Cooperative learning menurut Slavin (2005: 4-8) merujuk pada berbagai macam model pembelajaran di mana para siswa bekerja sama dalam kelompok-kelompok kecil yang terdiri dari berbagai tingkat prestasi, jenis kelamin, dan latar belakang etnik yang berbeda untuk saling membantu satu sama lain dalam mempelajari materi pelajaran. 
Dalam kelas kooperatif, para siswa diharapkan dapat saling membantu, saling mendiskusikan, dan berargumentasi untuk mengasah pengetahuan yang mereka kuasai saat itu dan menutup kesenjangan dalam pemahaman masing-masing. Cooperative learning lebih dari sekedar belajar kelompok karena dalam model pembelajaran ini harus ada struktur dorongan dan tugas yang bersifat kooperatif sehingga memungkinkan terjadi interaksi secara terbuka dan hubungan-hubungan yang bersifat interdependensi efektif antara anggota kelompok.

\section{Langkah-Lankah Pembelajaran Kooperatif}

Agus Suprijono (2009) memaparkan sintak model pembelajaran kooperatif terdiri dari enam fase sebagai berikut :

Tabel Fase-fase dalam pembelajaran Kooperatif dan Fase Kegiatan Guru

\begin{tabular}{|c|c|}
\hline Fase & Kegiatan Guru \\
\hline $\begin{aligned} \text { Fase } 1: & \text { Present goals and set } \\
& \text { Menyampaikan tujuan dan } \\
& \text { mempersiapkan siswa }\end{aligned}$ & $\begin{array}{l}\text { Menjelaskan tujuan pembelajaran } \\
\text { danmempersiapkan siswa siap belajar }\end{array}$ \\
\hline $\begin{aligned} \text { Fase } 2: & \text { Present information } \\
& \text { Menyajikan informasi }\end{aligned}$ & $\begin{array}{l}\text { Mempresentasikan informasi kepada } \\
\text { siswa secara verbal }\end{array}$ \\
\hline $\begin{aligned} & \text { Fase 3: } \text { Organize students into learning } \\
& \text { teams } \\
& \text { Mengorganisir siswa ke dalam } \\
& \text { tim-tim belajar } \\
&\end{aligned}$ & $\begin{array}{l}\text { Memberikan penjelasan kepada siswa } \\
\text { tentang tata cara pembentukan } \\
\text { tim belajar dan membantu kelompok } \\
\text { melakukan transisi yang efisien }\end{array}$ \\
\hline $\begin{array}{r}\text { Fase } 4: \text { Assist team work and studeny } \\
\text { Membantu kerja tim dan belajar }\end{array}$ & $\begin{array}{l}\text { Membantu tim-tim belajar selama siswa } \\
\text { mengerjakan tugasnya }\end{array}$ \\
\hline $\begin{array}{c}\text { Fase } 5: \text { Test on the Materials } \\
\text { Mengevaluasi }\end{array}$ & $\begin{array}{l}\text { Menguji pengetahuan siswa mengenai } \\
\text { berbagai materi pembelajaran atau } \\
\text { kelompok-kelompok mempresentasikan } \\
\text { hasil kerjanya }\end{array}$ \\
\hline $\begin{aligned} \text { Fase } 6 & \text { : Provide recognition } \\
& \text { Memberikan pengakuan atau } \\
& \text { penghargaan }\end{aligned}$ & $\begin{array}{l}\text { Mempersiapkan cara untuk mengakui } \\
\text { usaha dan prestasi individu maupun } \\
\text { kelompok }\end{array}$ \\
\hline
\end{tabular}

\section{Pembelajaran Kooperatif Tipe TAI (Team Assisted Individualization)}

Model Pembelajaran kooperatif tipe TAI (Team Assisted Individualization) ini dikembangkan oleh Slavin. Menurut Slavin (2005) tipe ini mengkombinasikan keunggulan pembelajaran kooperatif dan pembelajaran individual. Tipe ini dirancang untuk mengatasi kesulitan belajar siswa secara individual. Oleh karena itu kegiatan pembelajarannya lebih banyak digunakan untuk pemecahan masalah, ciri khas pada model pembelajaran TAI ini adalah setiap siswa secara individual belajar materi pembelajaran yang sudah dipersiapkan oleh guru. Hasil belajar individual dibawa ke kelompok-kelompok untuk didiskusikan dan saling dibahas oleh anggota kelompok, dan semua anggota kelompok bertanggung jawab atas keseluruhan jawaban sebagai tanggung jawab bersama. 
Model pembelajaran TAI dimana siswa dikelompokkan ke dalam kelompok kecil (4-5 siswa) secara heterogen yang dipimpin oleh seorang ketua kelompok yang mempunyai lebih dibandingkan anggotanya. Selain itu guru mempunyai fleksibilitas untuk berpindah dari kelompok ke kelompok atau dari individu ke individu, kemudian para siswa dapat saling memeriksa hasil kerja mereka, mengidentifikasi masalahmasalah yang muncul dalam kelompok dapat ditangani sendiri maupun dengan bantuan guru apabila diperlukan.

Miftahul (2011) mengemukakan bahwa dalam model pembelajaran TAI, siswa dikelompokkan berdasarkan kemampuannya yang beragam. Masing-masing kelompok terdiri dari 4-5 siswa dan ditugaskan untuk menyelesaikan materi pembelajaran atau PR. Dalam model pembelajaran TAI, setiap kelompok diberikan serangkaian tugas tertentu untuk dikerjakan bersama-sama. Masing-masing anggota diberi tes individu tanpa bantuan dari anggota yang lain. Selama menjalani tes individu ini, guru harus memperhatikan setiap siswa. Skor tidak hanya dinilai oleh sejauh mana siswa mampu menjalani tes itu, tetapi juga sejauh mana mereka mampu bekerja secara mandiri (tidak mencontek).

\section{METODOLOGI PENELITIAN \\ Tempat dan Waktu Penelitian}

Penelitian ini dilakukan di Kelas VIII SMP Negeri 2 Sampoiniet Kecamatan Sampoiniet Kabupaten Aceh Jaya, yang merupakan objek Penelitian. Penelitian direncanakan pada setiap hari Senin tanggal 12 Februari 2020untuk siklus 1 dan pada tanggal 26 Februari 2020 siklus II.

\section{Subjek Penelitian}

Subjek dalam penelitian ini adalah siswa Kelas VIII SMP Negeri 2 Sampoiniet sebanyak 25 orang yang terdiri dari laki-laki sebanyak 17 orang dan perempuan sebanyak 8 orang.

\section{Alat Pengumpulan Data}

Teknik pengumpulan data yang digunakan dalam penelitian ini terdiri dari 2 teknik, yaitu teknik observasi dan teknik tes.

\section{Teknik Analisis Data}

Teknik analisis data yang digunakan ada yang bersifat kuantitatif dan kualitatif. Data yang diperoleh dikatagorikan dan diklasifikasikan berdasarkan analisis kaitan logisnya, kemudian disajikan secara aktual dan sistematis dalam keseluruhan permasalahan dan kegiatan penelitian.

\section{Prosedur Penelitian}

Kegiatan penelitian ditempuh melalui prosedur yang ditentukan, yaitu melalui empat tahap, yaitu perencanaan pembelajaran, pelaksanaan pembelajaran, observasi dan pencatatan pembelajaran, dan analisis serta refleksi pembelajaran 


\section{HASIL PENELITIAN DAN PEMBAHASAN}

Dalam kegiatan orientasi dan identivikasi masalah terlebih dahulu dilakukan tes untuk mengetahui kemampuan siswa (tes awal) tentang materi belajar Macam-macam sujud.

\section{Deskripsi dan Pembahasan Siklus 1 \\ Tindakan Pembelajaran}

Tindakan pembelajaran yang akan dilaksanakan adalah dengan menggunakan Model Pembelajaran Kooperatif Tipe TAI, siswa dalam kegiatan belajar akan dikelompokkan kelompok, setiap kelompok terdiri dari 4-5 orang, dengan tujuan agar siswa dalam kelompok memperoleh kesempatan yang lebih banyak dalam melaksanakan kegiatan.

\section{Perencanaan}

Untuk menjaring data dalam penelitian, maka langkah selanjutnya membuat lembar observasi, antara lain :

1) Lembar observasi Rancangan Pelaksanaan Pembelajaran

2) Lembar observasi Pelaksanaan Pembelajaran

3) Lembar observasi Kemampuan Siswa pada Materi belajar Macam-macam sujud.

\section{Proses Pembelajaran}

Proses pembelajaran pada Siklus I meliputi kegiatan guru dalam mengajar, dan siswa dalam belajar dapat dilihat pada tabel berikut ini :

\section{Tabel Proses Pembelajaran Siklus I}

\begin{tabular}{|c|c|c|}
\hline No & Kegiatan Guru & Kegiatan Siswa \\
\hline \multirow[t]{4}{*}{1} & Kegiatan Awal & \\
\hline & $\begin{array}{l}\text {-Guru mengawali kegiatan mengajar } \\
\text { dengan mengkondisikan siswa pada } \\
\text { situasi mengajar yang kondusif } \\
\text { dengan melontarkan kata-kata } \\
\text { "anak-anak, sekarang kita akan } \\
\text { belajar PAI, tentang belajar Macam- } \\
\text { macam sujud" }\end{array}$ & $\begin{array}{l}\text { Siswa memperhatikan } \\
\text { pembicaraan guru, semula banyak } \\
\text { yang ngobrol }\end{array}$ \\
\hline & $\begin{array}{l}\text {-Guru menyampaikan informasi } \\
\text { tentang materi yang akan diajarkan, } \\
\text { termasuk menginformasikan belajar } \\
\text { kelompok }\end{array}$ & $\begin{array}{l}\text { Anak-anak kelihatan } \\
\text { semakinpenasaran ingin segera } \\
\text { pelajaran dimulai. }\end{array}$ \\
\hline & $\begin{array}{l}\text { - Guru memberikan apersepsi dengan } \\
\text { memberikan beberapa pertanyaan } \\
\text { yang ada hubungannya dengan } \\
\text { materi yang akan diajarkan }\end{array}$ & $\begin{array}{l}\text { Siswa menjawab pertanyaan guru } \\
\text { dengan baik, meski ada beberapa } \\
\text { orang yang kurang memperhatikan } \\
\text { guru, sehingga ketika diberi } \\
\text { Pertanyaan kebingungan }\end{array}$ \\
\hline 2 & Kegiatan Inti & \\
\hline & $\begin{array}{l}\text { - Guru menjelaskan tentang Materi } \\
\text { belajar Macam-macam sujud } \\
\text { Guru membagi siswa dalam } 4 \\
\text { kelompok, setiap kelompok terdiri }\end{array}$ & $\begin{array}{l}\text { Siswa memperhatikan penjelasan } \\
\text { guru meski ada beberapa orang } \\
\text { siswa yang kurang memper- } \\
\text { hatikan, akan tetapi ketika disuruh }\end{array}$ \\
\hline
\end{tabular}




\begin{tabular}{|c|c|c|}
\hline & $\begin{array}{l}\text { dari } 3 \text { dan } 4 \text { orang siswa. } \\
\text {-Guru memberikan lembar kerja } \\
\text { untuk dikerjakan dan dilaksanakan } \\
\text { oleh setiap kelompok } \\
\text { - Guru membimbing siswa dalam } \\
\text { melakukan kegiatan } \\
\text { - Guru menyuruh masuk keruangan } \\
\text { kelas untuk melaksanakan diskusi } \\
\text { kelompok } \\
\text {-Guru menjadi moderator dalam } \\
\text { kegiatan diskusi }\end{array}$ & $\begin{array}{l}\text { menjelaskan hampir semua siswa } \\
\text { memperhatikannya. } \\
\text { Siswa berkelompok berdasarkan } \\
\text { kelompoknya masing-masing } \\
\text { Siswa berkumpul masing-masing } \\
\text { kelompok } \\
\text { Siswa mengerjakan lembar kerja } \\
\text { meskipun setiap kelompok hanya } \\
\text { didominasi oleh siswa pandai } \\
\text { Semua siswa disuruh memasuki } \\
\text { kelas kembali untuk melaksanakan } \\
\text { kerja kelompok dan melaporkan } \\
\text { hasil kerja kelompok } \\
\text { Setiap kelompok melaporkan hasil } \\
\text { kegiatan kelompoknya dan } \\
\text { kelompok lain mendengarkan } \\
\text { untuk memberikan sanggahan }\end{array}$ \\
\hline 3 & Kegiatan Akhir & \\
\hline & $\begin{array}{l}\text {-Guru memberikan evaluasi sebanyak } \\
10 \text { soal } \\
\text {-Guru memberikan tindak lanjut } \\
\text { dengan memberikan Pekerjaan } \\
\text { Rumah }\end{array}$ & $\begin{array}{l}\text { Siswa mengerjakan soal yang } \\
\text { diberikan oleh guru }\end{array}$ \\
\hline
\end{tabular}

\section{Hasil Belajar Siswa Siklus I}

Berdasarkan data yang terkumpul dari hasil evaluasi yang dilaksanakan pada Siklus I, masih banyak siswa yang salah, secara rinci hasil yang diperoleh siswa adalah sebagai berikut :

Tabel Perolehan Nilai Pada Siklus I

\begin{tabular}{|c|l|c|c|c|c|}
\hline No & \multicolumn{1}{|c|}{ Nama Siswa } & L/P & KKM & Nilai & Ket \\
\hline 1 & Azizah & P & 72 & 85 & Tuntas \\
\hline 2 & Bilarunnah & P & 72 & 75 & Tuntas \\
\hline 3 & Ira Yuliana & P & 72 & 80 & Tuntas \\
\hline 4 & Maratus Shalehah & P & 72 & 75 & Tuntas \\
\hline 5 & Maulidar & P & 72 & 75 & Tuntas \\
\hline 6 & Muhammad Akbar & L & 72 & 75 & Tuntas \\
\hline 7 & Muhammad Farhan & L & 72 & 60 & Belum Tuntas \\
\hline 8 & Rangga Saputra & L & 72 & 85 & Tuntas \\
\hline 9 & Rio Revan & L & 72 & 75 & Tuntas \\
\hline 10 & Ritki Irsanda & L & 72 & 60 & Belum Tuntas \\
\hline 11 & Muhammad Zaki & L & 72 & 65 & Belum Tuntas \\
\hline 12 & Syahrizal & L & 72 & 60 & Belum Tuntas \\
\hline 13 & Irvanda & L & 72 & 55 & Belum Tuntas \\
\hline
\end{tabular}




\begin{tabular}{|c|c|c|c|c|c|}
\hline 14 & M. Fadhil Zaki Andrian & $\mathrm{L}$ & 72 & 80 & Tuntas \\
\hline 15 & M. Maulana & $\mathrm{L}$ & 72 & 75 & Tuntas \\
\hline 16 & M. Naufan Ramadhan & $\mathrm{L}$ & 72 & 75 & Tuntas \\
\hline 17 & Muhammad Syukran & $\mathrm{L}$ & 72 & 60 & Belum Tuntas \\
\hline 18 & Muqtadir & $\mathrm{L}$ & 72 & 65 & Belum Tuntas \\
\hline 19 & Nurhaliza & $\mathrm{P}$ & 72 & 60 & Belum Tuntas \\
\hline 20 & Muhammad Roni & $\mathrm{L}$ & 72 & 55 & Belum Tuntas \\
\hline 21 & Muhammad Husaini & $\mathrm{L}$ & 72 & 55 & Belum Tuntas \\
\hline 22 & Salman Alfarisi & $\mathrm{L}$ & 72 & 80 & Tuntas \\
\hline 23 & Sara Safitra & $\mathrm{P}$ & 72 & 75 & Tuntas \\
\hline 24 & Sirwati & $\mathrm{P}$ & 72 & 75 & Tuntas \\
\hline 25 & Wahyu Saputra & $\mathrm{L}$ & 72 & 55 & Belum Tuntas \\
\hline & Jumlah & $\mathrm{L}=\mathbf{1 7}$ & 1.800 & 1.735 & \multirow{2}{*}{ Tidak Tuntas } \\
\hline & Rata-rata & $\mathbf{P}=\mathbf{8}$ & 72 & 69 & \\
\hline
\end{tabular}

Tabel Refleksi Pembelajaran Siklus I

\begin{tabular}{|l|l|}
\hline \multicolumn{1}{|c|}{ Masalah Pembelajaran } & Hipotesis Tindakan Selanjutnya \\
\hline Kegiatan Guru & Tiap siswa dalam kelompok diberi \\
Guru telah dapat melaksanakan prosedurt tugas yang sama antara antara lain \\
pengajaran sesuai dengan skenario yang \\
ada pada relaksanakan praktek \\
meskipun masih ada keraguan dan siswa \\
yang tidak aktif kurang mendapat \\
perhatian dari guru.
\end{tabular}

\section{Deskripsi Dan Pembahasan Siklus 2}

Tindakan penelitian siklus 2 berdasarkan repleksi siklus 1, dan hasilnya disusun berdasarkan katagori data dibawah ini :

\section{Proses Pembelajaran}

Proses pembelajaran pada siklus 2 meliputi kegiatan guru dalam mengajar, dan siswa dalam belajar dapat dilihat pada tabel berikut ini :

Tabel Proses Pembelajaran Siklus 2

\begin{tabular}{|l|cr|c|}
\hline No. & \multicolumn{2}{|c|}{ Kegiatan Guru } & \multicolumn{1}{c|}{ Kegiatan Siswa } \\
\hline $\mathbf{1}$ & Kegiatan Awal & kegiatan \\
& $\begin{array}{l}\text { Guru mengawali } \\
\text { mengajar }\end{array}$ & -Siswa memperhatikan pembicaraan \\
& dengan dengan antusias
\end{tabular}




\begin{tabular}{|c|c|c|}
\hline & $\begin{array}{lrr}\text { mengkondisikan } & \text { siswa pada } \\
\text { situasi mengajar yang kondusif } \\
\text {-Guru menyampaikan } & \text { informasi } \\
\text { tentang materi yang akan } \\
\text { diajarkan, } & \text { termasuk } \\
\text { menginformasikan } & \text { belajar } \\
\text { kelompok } & \\
\text { - Guru memberikan apersepsi } \\
\text { dengan memberikan beberapa } \\
\text { pertanyaan yang } \\
\text { hubungannya dengan materi } \\
\text { yang akan diajarkan }\end{array}$ & $\begin{array}{l}\text { - Siswa menjawab pertanyaan guru } \\
\text { dengan baik, meski ada beberapa } \\
\text { siswa yang kurang memperhatikan } \\
\text { guru, sehingga ketika diberikan } \\
\text { pertanyaan kebingunan. }\end{array}$ \\
\hline 2 & $\begin{array}{l}\text { Kegiatan Inti } \\
\text { - Guru menjelaskan tentang } \\
\text { Konsep belajar Macam-macam } \\
\text { sujud } \\
\text { - Guru membagi siswa dalam } 7 \\
\text { kelompok, setiap kelompok } \\
\text { terdiri dari } 4 \text { sampai } 5 \text { orang } \\
\text { siswa. } \\
\text { - Guru membagikan LKS untuk } \\
\text { setiap kelompok } \\
\text { - Guru menyuruh setiap kelompok } \\
\text { untuk mengamati percobaan dan } \\
\text { memberikan lembar kerja untuk } \\
\text { dikerjakan oleh setiap kelompok } \\
\text { - Guru membimbinf siswa dalam } \\
\text { kerja kelompok } \\
\text { - Guru membimbing siswa untuk } \\
\text { menyimpulkan materi pelajaran }\end{array}$ & $\begin{array}{l}\text { - Siswa memperhatikan penjelasan } \\
\text { guru meski ada beberapa orang } \\
\text { siswa kurang } \\
\text { memperhatikan, akan tetapi ketika } \\
\text { disuruh menjelaskan hampir } \\
\text { semua siswa memperhatikannya. } \\
\text { - Siswa berkelompok berdasarkan } \\
\text { kelompoknya masing-masing. } \\
\text { - Siswa berkumpul masing-masing } \\
\text { kelompok } \\
\text { - Setiap kelompok melaksanakan } \\
\text { kegiatan kelompok sesuai dengan } \\
\text { petunjuk yang ada pada LKS } \\
\text { - Setiap siswa sangat diberi } \\
\text { kesempatan untuk melaporkan } \\
\text { hasil kerja kelompoknya dan } \\
\text { kelompok lain sebagai penanya }\end{array}$ \\
\hline 3 & $\begin{array}{l}\text { Kegiatan Akhir } \\
\text { - Guru memberikan Lembar } \\
\text { evaluasi } \\
\text { - Guru memberikan tindak lanjut } \\
\text { dengan memberikan Pekerjaan } \\
\text { Rumah }\end{array}$ & $\begin{array}{l}\text {-Siswa mengerjakan soal yang } \\
\text { diberikan oleh guru }\end{array}$ \\
\hline
\end{tabular}

\section{Hasil Belajar Siswa Siklus 2}

Berdasarkan data yang terkumpul dari hasil evaluasi yang dilaksanakan pada Siklus 2, masih banyak siswa yang salah, secara rinci hasil yang diperoleh siswa adalah sebagai berikut :

Tabel Perolehan Nilai Pos Tes Siklus 2

\begin{tabular}{|c|c|c|c|c|c|}
\hline No & Nama Siswa & L/P & KKM & HASIL & Ket \\
\hline 1 & Azizah & P & 72 & 85 & Tuntas \\
\hline
\end{tabular}




\begin{tabular}{|c|c|c|c|c|c|}
\hline 2 & Bilarunnah & $\mathrm{P}$ & 72 & 95 & Tuntas \\
\hline 3 & Ira Yuliana & $\mathrm{P}$ & 72 & 85 & Tuntas \\
\hline 4 & Maratus Shalehah & $\mathrm{P}$ & 72 & 80 & Tuntas \\
\hline 5 & Maulidar & $\mathrm{P}$ & 72 & 80 & Tuntas \\
\hline 6 & Muhammad Akbar & $\mathrm{L}$ & 72 & 75 & Tuntas \\
\hline 7 & Muhammad Farhan & $\mathrm{L}$ & 72 & 85 & Tuntas \\
\hline 8 & Rangga Saputra & $\mathrm{L}$ & 72 & 85 & Tuntas \\
\hline 9 & Rio Revan & $\mathrm{L}$ & 72 & 85 & Tuntas \\
\hline 10 & Ritki Irsanda & $\mathrm{L}$ & 72 & 75 & Tuntas \\
\hline 11 & Muhammad Zaki & $\mathrm{L}$ & 72 & 70 & Tuntas \\
\hline 12 & Syahrizal & $\mathrm{L}$ & 72 & 80 & Tuntas \\
\hline 13 & Irvanda & $\mathrm{L}$ & 72 & 70 & Tuntas \\
\hline 14 & M. Fadhil Zaki Andrian & $\mathrm{L}$ & 72 & 85 & Tuntas \\
\hline 15 & M. Maulana & $\mathrm{L}$ & 72 & 95 & Tuntas \\
\hline 16 & M. Naufan Ramadhan & $\mathrm{L}$ & 72 & 85 & Tuntas \\
\hline 17 & Muhammad Syukran & $\mathrm{L}$ & 72 & 80 & Tuntas \\
\hline 18 & Muqtadir & $\mathrm{L}$ & 72 & 80 & Tuntas \\
\hline 19 & Nurhaliza & $\mathrm{P}$ & 72 & 75 & Tuntas \\
\hline 20 & Muhammad Roni & $\mathrm{L}$ & 72 & 85 & Tuntas \\
\hline 21 & Muhammad Husaini & $\mathrm{L}$ & 72 & 85 & Tuntas \\
\hline 22 & Salman Alfarisi & $\mathrm{L}$ & 72 & 95 & Tuntas \\
\hline 23 & Sara Safitra & $\mathrm{P}$ & 72 & 85 & Tuntas \\
\hline 24 & Sirwati & $\mathrm{P}$ & 72 & 80 & Tuntas \\
\hline 25 & Wahyu Saputra & $\mathrm{L}$ & 72 & 80 & Tuntas \\
\hline & Jumlah & $\mathrm{L}=\mathbf{1 7}$ & 1.800 & 2.060 & \multirow{2}{*}{ Tuntas } \\
\hline & Rata-rata & $\mathbf{P}=\mathbf{8}$ & 72 & 82 & \\
\hline
\end{tabular}

Tabel Refleksi Pembelajaran Siklus 2

\begin{tabular}{|c|c|}
\hline Mas: & is Tindakan Selar \\
\hline $\begin{array}{l}\text { A. Kegiatan Guru } \\
\text { Guru telah dapat melaksanakan } \\
\text { prosedur pengajaran sesuai dengan } \\
\text { skenario rencana pembelajaran, } \\
\text { meskipun masih ada keraguan } \\
\text { dari siswa yang kurang mendapat } \\
\text { perhatian dari guru. } \\
\text { B. Kegiatan Siswa } \\
\text { Siswa secara umum tampak memiliki } \\
\text { minat yang tinggi dalam belajar, akan } \\
\text { tetapi masih perlu penjelasan guru } \\
\text { dalammengerjakan LKS }\end{array}$ & $\begin{array}{l}\text { b. Siswa dibimbing secara intensif } \\
\text { secara individu, baik dalam } \\
\text { kegiatan menjelaskan maupun } \\
\text { dalam mengerjakan LKS }\end{array}$ \\
\hline
\end{tabular}


Berdasarkan hasil penelitian pada Siklus 2 maka hasil refleksi selama kegiatan pada penelitian yang dimulai dari persiapan sampai pada pelaksanaan dianggap sudah berhasil, hal ini berdasarkan tingkat kemampuan siswa yang amat baik.

Berdasarkan hasil penelitian bahwa jumlah siswa dan persentase siswa yang terlibat aktif dalam pembelajaran sebelum perbaikan pembelajaran menunjukkan adanya kenaikan, sebelum perbaikan pembelajaran siswa yang terlibat aktif hanya hanya 11 orang (44\%) kemudian naik pada siklus II menjadi 23 orang (92\%). Hal ini menunjukkan bahwa aktivitas belajar siswa dalam pembelajaran PAI mengalami peningkatan. Peningkatan aktivitas belajar siswa tersebut tersaji pada grafik dibawah ini.

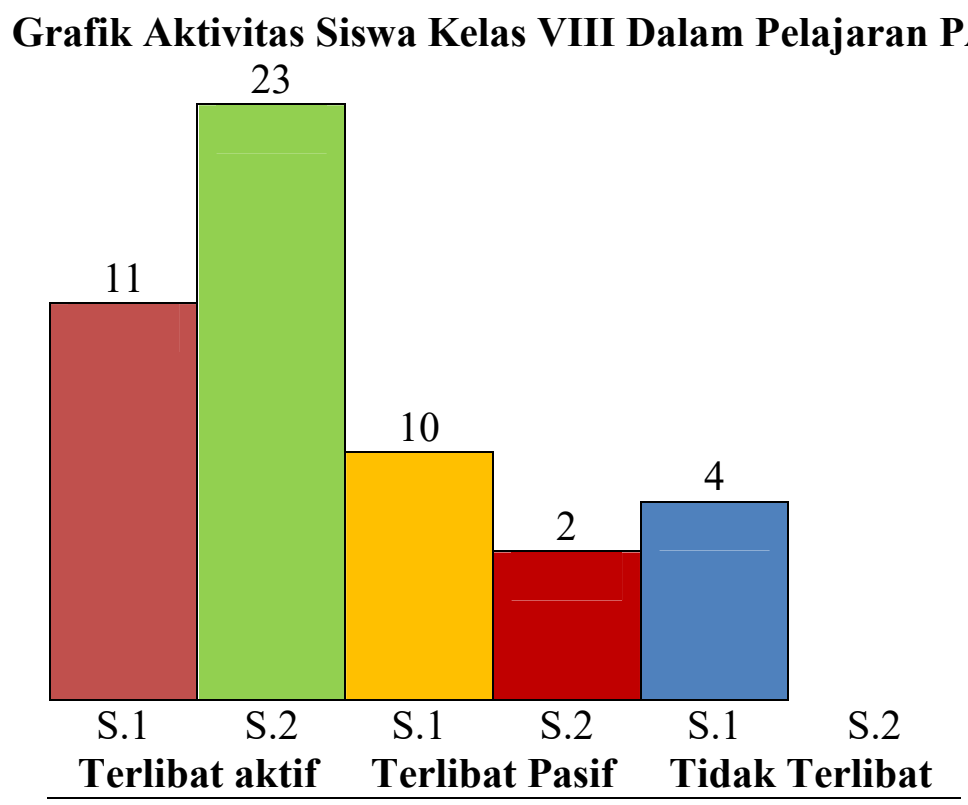

Tabel Hasil Belajar Siswa dalam Pembelajaran

\begin{tabular}{|c|c|c|c|c|c|}
\hline \multirow{2}{*}{$\begin{array}{c}\text { Interval } \\
\text { Nilai }\end{array}$} & \multicolumn{2}{|c|}{ Siklus I } & \multicolumn{2}{c|}{ Siklus II } & \multirow{2}{*}{ Kategori } \\
\cline { 2 - 5 } & Frekuensi & Persen & Frekuensi & Persen & \\
\hline $75-100$ & 13 & $52 \%$ & 25 & $100 \%$ & Tuntas \\
\hline $0-74$ & 12 & $48 \%$ & 0 & $0 \%$ & Tidak Tuntas \\
\hline
\end{tabular}

Dari data di atas dapat terlihat bahwa hasil belajar siswa cenderung meningkat. Sebelum pembelajaran siswa yang sudah tuntas belajar sebanyak 13 orang siswa (52\%), pada dan siklus II bertambah menjadi 25 orang siswa $(100 \%)$

\section{Kesimpulan}

Penelitian Tindakan Kelas (PTK) untuk meningkatkan pemahaman siswa tentan belajar dengan menggunakan model Pembelajaran Kooperatif Tipe TAI dalam pembelajaran PAI di Kelas VIII SMP Negeri 2 Sampoiniet Kabupaten Aceh Jaya, berdasarkan hasil penelitian dapat disimpulkan yaitu langkah-langkah persiapan yang telah direncanakan untuk pelaksanaan penelitian berjalan sesuai dengan rencana, dari mulai pembuatan Rencana Pelaksanaan Pembelajaran (RPP) sampai pembuatan instrumen yaitu lembar observasi untuk rencana pelajaran, lembar observasi untuk 
aktivitas guru dalam mengajar dan lembar observasi untuk kegiatan siswa dalam belajar, telah berhasil menjaring data sebagai hasil penelitian. Pelaksanaan pembelajaran tentang belajar Macam-macam sujud dengan menggunakan model Pembelajaran Kooperati Tipe TAI, berjalan sesuai dengan skenario yang ada pada Rencana Pelaksanaan Pembelajaran (RPP), dan telah berhasil menciptakan situasi belajar yang kondusif yakni siswa terlibat secara langsung pada proses pembelajaran, juga dapat meningkatkan motivasi siswa untuk belajar PAI yang semula dianggap sulit. Tingkat pemahaman siswa tentang belajar Macam-macam sujud setelah pembelajaran menggunakan model Pembelajaran Kooperatif Tipe TAI dapat meningkat dengan baik, ini dapat dilihat dari hasil evaluasi yaitu pada siklus ke 1 memperoleh nilai rata-rata $69 \%$ dan pada siklus 2 memperoleh nilai rata-rata hingga $82 \%$.

\section{DAFTAR PUSTAKA}

Badan Standar Nasional Pendidikan. (2006). Panduan Penyusunan Kurikulum Tingkat Tingkat Satuan Pendidikan Jenjang Pendidikan Dasar dan Menengah. Jakarta: BSNP

Depdiknas, (2004). Kurikulum Pendidikan Menengah, Dirjen Dikdasmen.

Depdikbud, (1998). Petunjuk Pelaksanaan Kegiatan Belajar Mengajar Kelas VIII Sekolah Menengah. Jakarta Dirjen Dikdasmen.

Kasihani Kasbolah, (1998). Penelitian Tindakan Kelas Dirjen Pendidikan. Tinggi Proyek Pendidikan Guru Sekolah Menengah.

Nana Sujana, (1991). Media Pengajaran. Pusat Penelitian dan Pembidangan Ilmu Lembaga Penelitian IKIP Bandung. Sinar Baru.

Ngalimun Purwanto, (1997). Psikologi Pendidikan. Bandung Remaja RoSMPa Karya. Tim Bina Karya Guru, (2008). PAI SMP/MI untuk Sekolah Menenahg Kelas VIII. Jakarta : Penerbit Erlangga.

Slavin dan dkk. (2005). Model-model Pembelajaran kooperatif. Jakarta: Dapdiknas Sumarwan, dkk, PAI SMP/MI Untuk Kelas VIII, Jakarta: Erlangga, 2017. 